\title{
Fetal Urine Production in Late Pregnancy
}

\author{
Robert H. Stigter, Eduard J. H. Mulder, Hein W. Bruinse, and Gerard H. A. Visser \\ Department of Perinatology \& Gynecology, Wilhelmina Children's Hospital, University Medical Centre Utrecht, Lundlaan 6, \\ 3584 EA Utrecht, The Netherlands
}

Correspondence should be addressed to Eduard J. H. Mulder, emulder@umcutrecht.nl

Received 8 April 2011; Accepted 10 May 2011

Academic Editors: D. Chen, J. G. Schenker, and K. Yang

Copyright ( $) 2011$ Robert H. Stigter et al. This is an open access article distributed under the Creative Commons Attribution License, which permits unrestricted use, distribution, and reproduction in any medium, provided the original work is properly cited.

\begin{abstract}
Objective. Hourly fetal urine production rate (HFUPR) was studied in relation to both gestational age and the onset of spontaneous labor in normal term human pregnancies. Methods. Serial volume measurements were obtained from longitudinal ultrasound images of the fetal bladder at 1-5-minute intervals, and HFUPR was subsequently calculated. A total of 178 adequate bladder-filling cycles were recorded in 112 women, and the amniotic fluid index (AFI) was assessed. Results. HFUPR did not change significantly between 37 and 42 weeks' gestation. However, HFUPR decreased during the last 14 days prior to the onset of spontaneous labor $(P<0.005)$. No significant correlation was found between HFUPR and AFI, neither when measured at the same time nor when HFUPR and AFI were measured at various intervals in time. Conclusion. HFUPR falls before and in relation to the time of onset of labor rather than in relation to gestational age.
\end{abstract}

\section{Introduction}

Prolongation of pregnancy beyond term is often associated with oligohydramnios and with increased perinatal mortality and morbidity [1-3]. Several studies have shown a relationship between the presence of oligohydramnios and an unfavourable pregnancy outcome, regardless of gestational age $[1,4-7]$. The ultrasonographic assessment of the quantity of amniotic fluid, often expressed as the amniotic fluid index (AFI), is an important parameter of fetal monitoring in prolonged pregnancy [7]. The AFI, the sum of the deepest amniotic fluid pockets in four abdominal quadrants, has been shown to be a reproducible test and was found to correlate well with volumes determined by dilution methods $[8,9]$. A reduction in the amount of amniotic fluid in pregnancies beyond term is often reported. This has been shown in invasive studies of cross-sectional design using a variety of dilution techniques [10] and by ultrasound measurement of the AFI in longitudinal studies [11, 12]. Recently we found no reduction in the AFI with advancing gestation in accurately dated pregnancies, but a significant reduction in relation to the time of onset of spontaneous labor [13].
The quantity of amniotic fluid in third trimester pregnancy is the result of contributions from fetal urine and the secretion of fetal lung liquid on the one hand, and the removal of fluid by fetal swallowing and resorption through the fetal membranes on the other hand [14]. The mechanisms responsible for the regulation of the amniotic fluid volume are unknown. It is often assumed that the features of postterm pregnancy are the result of placental insufficiency and growth delay [15-18]. There are similarities between clinical features of intrauterine growth retardation (IUGR) occurring earlier in pregnancy and postterm pregnancy. In the growth-retarded fetus changes in the circulation occur, favouring the brain, adrenals, and coronary arteries at the expense of other organ systems such as the digestive system and renal tract, a phenomenon known as "brain sparing" or "redistribution." In the growth-retarded fetus the reduced perfusion of the fetal kidneys is deemed responsible for a reduction of fetal urine output and a subsequent reduction of the amniotic fluid volume.

It was the purpose of this study to examine hourly fetal urine production rate (HFUPR) in relation to both gestational age and the time of onset of spontaneous labor in term pregnancies. We also examined the relationship between HFUPR and AFI. 


\section{Patients and Methods}

2.1. Patients. The study was approved by the ethics committee of University Medical Centre Utrecht, and informed consent was obtained from all women. A total of 142 women with uncomplicated singleton pregnancies were recruited from the outpatient clinic. Hourly fetal urine production rate (HFUPR) and amniotic fluid index (AFI) were assessed at weekly intervals between 37 and 41 weeks and then twice weekly until delivery. AFI was determined during 220 sessions, and HFUPR was assessed in 200 recordings. HFUPR recordings did not fulfill predefined quality criteria (see below) in 13 sessions, leaving 187 HFUPR measurements in 117 women for further analysis. A single HFUPR measurement was available from 75 of the 117 women, while more than one HFUPR recording was available from 42 women (23 had 2, 15 had 3, one had 4, one had 5, and 2 had 6 recordings each).

The women had been recruited at a mean gestational age of 277 days (range 249-295 days). Sixty-nine (59\%) women were nulliparous. Gestational age (GA) was calculated from a first-trimester crown-rump length (CRL) measurement in $95(81 \%)$ cases or from the last menstrual period (LMP) if no first trimester ultrasound measurements were available. Gestational age was based on uncertain LMP in 4 cases. Labor onset was spontaneous in $89(76 \%)$ women. Mean number of days prior to spontaneous delivery was 10 (SD 7, range 0 35). Gestational age at delivery ranged between 266 and 302 days (mean 287 days). Mean birth weight was 3552 (SD 471) grams, and 48 girls and 69 boys were born. The 5-minute Apgar score was $\geq 7$ in all cases.

2.2. Methods. All examinations were performed by a single investigator (RHS) by means of a colour Doppler ultrasound machine (Toshiba SSH 140A, Toshiba Medical Systems Division, Tokyo, Japan) fitted with a $3.75 \mathrm{MHz}$ curved array transducer. Examinations were all carried out between 14:00 and 17:00 h, and care was taken to perform repeat measurements in each individual at the same time of day [19]. The AFI was determined at the beginning of each session as described by Phelan et al. [20], with the woman in supine position. On completion of the AFI measurement the woman was placed in a more comfortable semi recumbent position. Ultrasound biometry was next performed to estimate fetal weight. A CTG monitor (Hewlett Packard 8040A) was used for continuous recording of the fetal heart rate throughout the remainder of the investigation (mean duration $46 \mathrm{~min}$, range $21-83 \mathrm{~min}$ ). All fetal heart rate recordings showed normal patterns.

Fetal bladder volume measurements were performed using the method introduced by Hedriana and Moore which showed a better correlation with known bladder volumes than previously used methods [21]. We adapted the technique by averaging the results of bladder volume calculations from the equations for exact coronal and sagittal planes as described previously [22]. A longitudinal section was obtained of the entire fetus and the largest outline of the fetal bladder selected by making parallel scans on either side of the original plane, as described by Campbell et al.

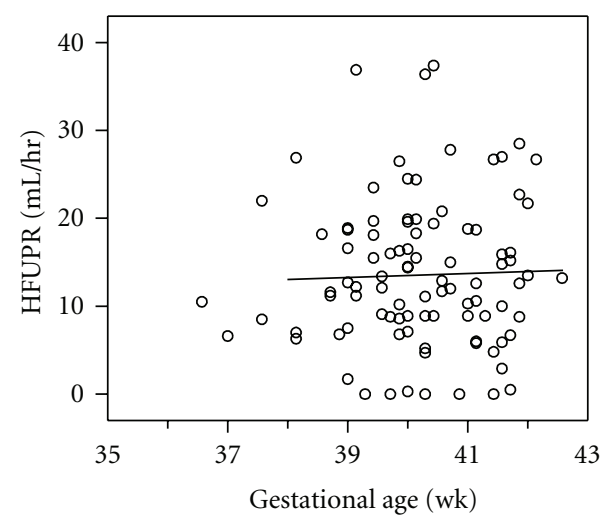

FIGURE 1: Relationship between hourly fetal urine production rate (HFUPR) and gestational age in 95 cases with accurately dated pregnancy. Only the last measurement from an individual case was used if more than one measurement was available.

[23]. Images were obtained at 1-5-minute intervals, printed on a strip chart recorder, and subsequently scanned for offline analysis. The surface area of the longitudinal section of the fetal bladder was calculated by tracing the outline using a computer software program (NIH image) on a standard personal computer. Fetal bladder volumes were calculated from the equation Vol. $=0.84+1.23 \times$ bladder area, the mathematical average of the equations for exact sagittal and coronal measurements provided by Hedriana and Moore [21] and Stigter et al. [22]. HFUPR was calculated from the slope of the regression line through the individual bladder volume measurements as described by Rabinowitz et al. [24] Cases were included only if a minimum of 6 individual bladder volume measurements (mean number 13, range 643) were available, and the interval between the first and last measurements of a series of bladder volume measurements was $\geq 15 \mathrm{~min}$ (mean interval $29 \mathrm{~min}$, range 15-59 min).

2.3. Data Analysis. The relationship between HFUPR and gestational age was examined by using only the last HFUPR measurement of any individual where gestational age had been calculated from a first trimester CRL measurement. When examining the relationship between HFUPR and the time of onset of labor, the accuracy of gestational age was not essential, and again only the last measurement from each individual who labored spontaneously was included.

The relationship between HFUPR and AFI at various time points in the cases with repeat measurements was analysed by randomly selecting combinations for each individual out of 108 possible combinations.

SPSS for Windows (version 16.01, SPSS Inc., Chicago, Ill) was used for data management and statistical analysis. Data were analysed by linear regression analysis, 1-way ANOVA, or linear mixed model analysis (in case of repeated measurements). Significance was assumed at $P<0.05$.

\section{Results}

The last HFUPR measurements obtained from 95 individuals with accurately dated pregnancies are shown in Figure 1. 
TABLE 1: Final HFUPR measurement and time to onset of spontaneous labor with $(\mathrm{mL} / \mathrm{kg} / \mathrm{h})$ and without correction for estimated fetal weight $(\mathrm{mL} / \mathrm{h})$. Data are presented as 3-day categories. No data were available on estimated fetal weight in 5 cases.

\begin{tabular}{|c|c|c|c|c|}
\hline \multirow{2}{*}{ Number of days to onset delivery } & \multicolumn{2}{|c|}{$\operatorname{HFUPR}(\mathrm{mL} / \mathrm{h})$} & \multicolumn{2}{|c|}{ HFUPR (mL/kg/h) } \\
\hline & No. & mean (SEM) & No. & mean (SEM) \\
\hline-9 to -11 & 10 & $14.1(1.7)$ & 10 & $4.7(0.5)$ \\
\hline-6 to -8 & 10 & $17.5(3.2)$ & 8 & $5.9(1.3)$ \\
\hline-3 to -5 & 29 & $16.5(1.7)$ & 29 & $5.3(0.6)$ \\
\hline 0 to -2 & 30 & $10.2(1.4)^{*}$ & 27 & $3.5(0.5)^{* *}$ \\
\hline
\end{tabular}

${ }^{*} P<0.02$; ${ }^{*} P<0.05$ compared with the other 3 -day categories (1-way ANOVA with Bonferroni correction).

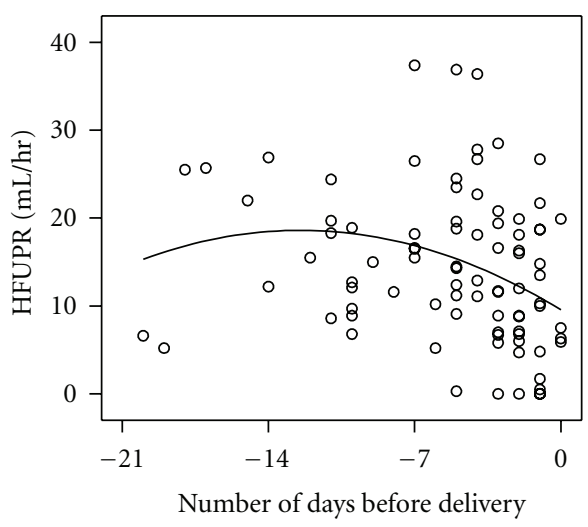

FIGURE 2: Relationship between hourly fetal urine production rate (HFUPR) and time of onset of spontaneous labor ( $n=89$ cases). Only the last measurement from an individual case was used if more than one measurement was available.

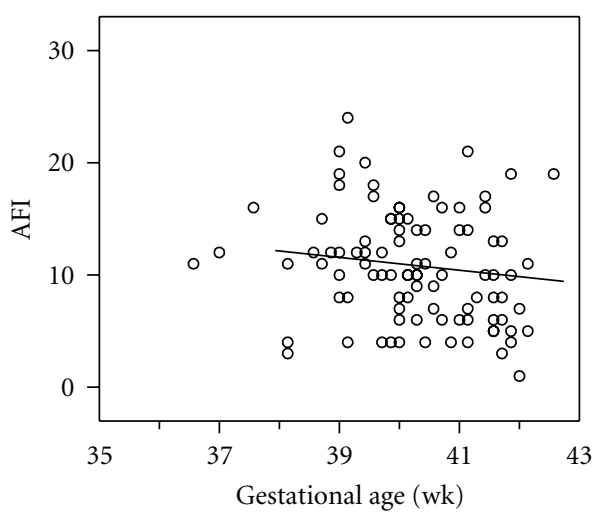

FIGURE 3: Relationship between amniotic fluid index (AFI) and gestational age in 95 cases with accurately dated pregnancy. Only the last measurement from an individual case was used if more than one measurement was available.

There was no significant change in HFUPR between 38 and 42 weeks' gestation. The same was true for HFUPR corrected for estimated fetal weight (data not shown). Linear mixed model analysis for the group of 42 women with at least 2 repeated measurements also showed no significant change in HFUPR with advancing gestation $(\beta=-0.10$; SE 0.13 ; df $=$ 80; $P=0.44)$.

The last HFUPR measurements recorded in each individual who labored spontaneously $(n=89)$ are shown in

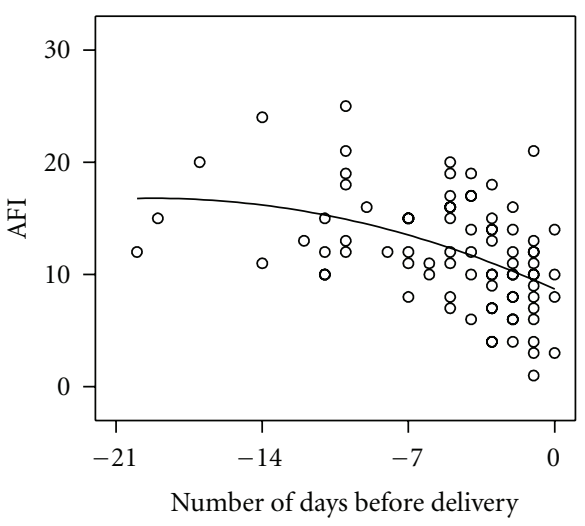

FIGURE 4: Relationship between amniotic fluid index (AFI) and time of onset of spontaneous labor ( $n=87$ cases). Only the last measurement from an individual case was used if more than one measurement was available.

Figure 2. A polynomial regression line fitted the data best: $y=9.56-1.45 \times$ (number of days to delivery) $-0.058 \times$ (number of days to delivery) $^{2}$. HFUPR decreased linearly over the last 14 days before the onset of labor $(\beta=-0.62$; $n=80, P<0.005$ ), especially during the last 3 days (Table 1 ). Linear mixed model analysis in the group of women with $\geq 2$ repeated measurements also demonstrated a significant fall in HFUPR during the last two weeks before delivery $(\beta$ $=-0.70$; SE $0.31 ; \mathrm{df}=44 ; P<0.05)$. Similar results were obtained for HFUPR corrected for estimated fetal weight (data not shown).

AFI values were normalised for gestational age based on the normal values described by Nwosu et al. [12] and expressed as $z$-score. The AFI values and their $z$-scores were highly correlated $(R=0.97 ; P<0.0001 ; n=197)$. In women with accurately dated pregnancies, AFI values obtained during the final session did not change significantly between 38 and 42 weeks' gestation (Figure 3; $\beta=-0.24$, $P=0.094, n=92)$. A similar observation was made in the cases with $\geq 2$ repeated measurements $(\beta=-0.09$, SE 0.06, $\mathrm{df}=57, P=0.12)$. However, in the cases with spontaneous labor, the last AFI values declined over the 14 days prior to delivery (Figure $4 ; \beta=-0.62, P<0.001, n=82$ ), which was also true for individual cases with repeated measurements over the last 14 days $(\beta=-0.13$, SE $0.06, \mathrm{df}=42, P<0.05)$.

We examined the relationship between HFUPR and AFI (absolute values and $z$-scores) during the same session in all 
TABLE 2: Relationship between measurements of AFI and HFUPR in individuals with repeat measurements at various time intervals. Data are presented as correlation coefficient $(R)$ and $P$ values, $n=$ number of measurements.

\begin{tabular}{lcccccccc}
\hline $\begin{array}{l}\text { Median } \\
\text { interval (days) }\end{array}$ & $\begin{array}{l}\text { Range } \\
\text { (days) }\end{array}$ & $n$ & \multicolumn{3}{c}{$\begin{array}{c}\text { AFI at time 1 versus AFI at } \\
\text { time 2 }\end{array}$} & \multicolumn{2}{c}{$\begin{array}{c}\text { HFUPR at time 1 versus } \\
\text { HFUPR at time 2 }\end{array}$} & \multicolumn{2}{c}{$\begin{array}{c}\text { HFUPR at time 1 } \\
\text { versus AFI at time 2 } \\
R\end{array}$} \\
\hline 3 & $1-4$ & 16 & 0.84 & $<0.0001$ & 0.21 & NS & -0.34 & NS \\
7 & $5-7$ & 24 & 0.55 & $<0.005$ & -0.27 & NS & 0.03 \\
10 & $8-13$ & 20 & 0.53 & $<0.02$ & -0.07 & NS & 0.25 \\
17 & $14-21$ & 16 & 0.51 & $<0.05$ & -0.17 & NS & -0.29 \\
\hline
\end{tabular}

cases and the effect of various time intervals between sessions in the serial data sets from 42 cases (Table 2). HFUPR values were not corrected for gestational age since changes over the time intervals studied are negligible. No significant correlation was found between the HFUPR and AFI values obtained during the same session $(R=0.08$ and $R=0.07$ for $z$-scores; $n=183$ ). Good correlations were found between serial AFI measurements within individuals at intervals of up to two weeks, but not for HFUPR values obtained within individuals at various time intervals (Table 2). HFUPR and AFI (or $z$-scores) were not significantly correlated for any of the studied time intervals (Table 2).

\section{Discussion}

Using an adaptation of the method introduced by Hedriana and Moore [21], we found no significant change of the hourly fetal urine production rate with advancing gestational age between 38 and 42 weeks' gestation in accurately dated pregnancies, with or without correction for estimated fetal weight. However, we did find a significant reduction of the HFUPR during the last 14 days prior to the onset of spontaneous labor. No significant correlation was found between fetal urine production rate and AFI.

Previous reports on fetal urine production rates, using the measurement technique introduced by Campbell et al. [23], are flawed because bladder volume measurements were made too infrequently. Complete or partial emptying of the fetal bladder must have been overlooked in between consecutive measurements, leading to an underestimation of fetal urine output. The subsequent modifications introduced by Rabinowitz et al. [24] should have overcome this problem, yet were found by Hedriana and Moore [21] to result in a considerable overestimation of fetal urine production. In an earlier study, using the method introduced by Rabinowitz et al. [24], we found a significant positive correlation between calculated HFUPR and the maximum bladder volume at the end of a series of measurements, suggesting a progressive error [25]. Hedriana and Moore [21] showed a good correlation between known bladder volumes and volumes calculated from a sagittal or coronal area measurement only ( $R=0.95$ and $R=0.94$, resp.). The accuracy of their technique to determine HFUPR showed no improvement beyond 6 individual measurements of bladder volume in a filling cycle. Rabinowitz et al. [24] did not define a minimum number of individual volume measurements to reliably calculate HFUPR, nor did they suggest a minimum duration for the period of observation, which may explain the unrealistic values of more than $100 \mathrm{~mL} / \mathrm{h}$, observed in some studies. The maximum bladder volumes and urine production rates found in our study are more in keeping with neonatal data and with observed urine production rates in animal experiments. We found no indication for a reduction in fetal urine production with increasing gestation, as reported in a number of studies [26, 27]. No previous study has examined fetal urine production in relation to the time of onset of labor. However, Wlodek et al. found no change in the number of voids between 125 and 144 days' gestation in sheep fetuses but a significant decrease in the number of voids during the last 5 days before onset of labor, which suggests a possible decrease in the rate of urine production during this period [28].

In contrast with others, we found no significant relationship between HFUPR and AFI measured at the same time [29]. It is reasonable to assume that a decrease in fetal urine production does not have an immediate effect on the amount of amniotic fluid as a number of other mechanisms are involved in maintaining the quantity of amniotic fluid at a constant level. An example of the potential of these compensatory mechanisms can be found in a study by Minei and Suzuki [30], where occlusion of the oesophagus in primate fetuses resulted in only a transient increase of the amniotic fluid volume. In our study AFI measurements remained constant for periods of up to two weeks, but HFUPR measurements showed considerable variation within individuals. The effect of fetal behavioural state changes on the variation in HFUPR measurements in near-term pregnancy, as suggested in one study [31], was found to be the result of the progressive measurement error with increasing volumes inherent to the Rabinowitz' method and the fact that the fetus usually voids at the transition from state $1 \mathrm{~F}$ to $2 \mathrm{~F}[25]$. The variability in HFUPR values within individuals observed in our study could still be the result of measurement errors, may reflect true short-term fluctuations of fetal urine production or a combination of both, and this precludes the useful analysis of changes within individuals.

Recently, we found a significant reduction in AFI in relation to the onset of labor, but not in relation to gestational age in accurately dated pregnancies [13]. We conclude that it is likely that the reduction in fetal urine production contributes to the reduction in amniotic fluid in the period before onset of labor, but the large variation 
in HFUPR measurements prevents the establishment of a direct relationship within individuals. The reduction in fetal urine production and amniotic fluid is related to physiological changes occurring in preparation of labor and is not related to gestational age. The reduction in fetal urine production may at least in part be the result of circulatory "redistribution" and subsequent reduced renal perfusion that was observed in these pregnancies and reported previously [32].

\section{References}

[1] P. F. Chamberlain, F. A. Manning, and I. Morrison, "Ultrasound evaluation of amniotic fluid volume. I. The relationship of marginal and decreased amniotic fluid volumes to perinatal outcome," American Journal of Obstetrics and Gynecology, vol. 150, no. 3, pp. 245-249, 1984.

[2] R. L. Naeye, "Causes of perinatal mortality excess in prolonged gestations," American Journal of Epidemiology, vol. 108, no. 5, pp. 429-433, 1978.

[3] L. Bakketeig and P. Bersjo, "Post-term pregnancy: magnitude of the problem," in Effective Care in Pregnancy and Childbirth, I. Chalmers, M. Enkin, and M. J. N. C. Keirse, Eds., pp. 765775, Oxford University Press, Oxford, UK, 1989.

[4] L. J. Mercer, L. G. Brown, R. E. Petres, and R. H. Messer, "A survey of pregnancies complicated by decreased amniotic fluid," American Journal of Obstetrics and Gynecology, vol. 149, no. 3, pp. 355-361, 1984.

[5] A. Bastide, F. Manning, and C. Harman, "Ultrasound evaluation of amniotic fluid: outcome of pregnancies with severe oligohydramnios," American Journal of Obstetrics and Gynecology, vol. 154, no. 4, pp. 895-900, 1986.

[6] W. F. Rayburn, M. E. Motley, L. E. Stempel, and R. M. Gendreau, "Antepartum prediction of the postmature infant," Obstetrics and Gynecology, vol. 60, no. 2, pp. 148-153, 1982.

[7] P. Crowley, C. O'Herlihy, and P. Boylan, “The value of ultrasound measurement of amniotic fluid volume in the management of prolonged pregnancies," British Journal of Obstetrics and Gynaecology, vol. 91, no. 5, pp. 444-448, 1984.

[8] S. E. Rutherford, C. V. Smith, J. P. Phelan, K. Kawakami, and M. O. Ahn, "Four-quadrant assessment of amniotic fluid volume. Interobserver and intraobserver variation," Journal of Reproductive Medicine for the Obstetrician and Gynecologist, vol. 32, no. 8, pp. 587-589, 1987.

[9] G. A. Dildy, N. Lira, K. J. Moise, G. D. Riddle, and R. L. Deter, "Amniotic fluid volume assessment: comparison of ultrasonographic estimates versus direct measurements with a dye-dilution technique in human pregnancy," American Journal of Obstetrics and Gynecology, vol. 167, no. 4, pp. 986994, 1992.

[10] R. A. Brace and E. J. Wolf, "Normal amniotic fluid volume changes throughout pregnancy," American Journal of Obstetrics and Gynecology, vol. 161, no. 2, pp. 382-388, 1989.

[11] A. D. Marks and M. Y. Divon, "Longitudinal study of the amniotic fluid index in post-dates pregnancy," Obstetrics and Gynecology, vol. 79, no. 2, pp. 229-233, 1992.

[12] E. C. Nwosu, C. R. Welch, P. R. Manasse, and S. A. Walkinshaw, "Longitudinal assessment of amniotic fluid index," British Journal of Obstetrics and Gynaecology, vol. 100, no. 9, pp. 816819, 1993.

[13] R. H. Stigter, E. J. H. Mulder, H. W. Bruinse, and G. H. A. Visser, "The amniotic fluid index in late pregnancy," Journal of
Maternal-Fetal and Neonatal Medicine, vol. 12, no. 5, pp. 291297, 2002.

[14] W. M. Gilbert and R. A. Brace, "The missing link in amniotic fluid volume regulation: intramembranous absorption," Obstetrics and Gynecology, vol. 74, no. 5, pp. 748-754, 1989.

[15] P. Gruenwald, "Growth of the human fetus. I. Normal growth and its variation," American Journal of Obstetrics and Gynecology, vol. 94, no. 8, pp. 1112-1119, 1966.

[16] R. L. Naeye and J. B. Dixon, "Distortions in fetal growth standards," Pediatric Research, vol. 12, no. 10, pp. 987-991, 1978.

[17] T. Bjerkedal, L. Bakketeig, and E. H. Lehmann, "Percentiles of birth weights of single, live births at different gestation periods: based on 125,485 births in Norway, 1967 and 1968," Acta Paediatrica Scandinavica, vol. 62, no. 5, pp. 449-457, 1973.

[18] H. Vorherr, "Placental insufficiency in relation to postterm pregnancy and fetal postmaturity. Evaluation of fetoplacental function; management of the postterm gravida," American Journal of Obstetrics and Gynecology, vol. 123, no. 1, pp. 67103, 1975.

[19] R. A. Brace and T. R. Moore, "Diurnal rhythms in fetal urine flow, vascular pressures, and heart rate in sheep," American Journal of Physiology, vol. 261, no. 4, pp. R1015-R1021, 1991.

[20] J. P. Phelan, C. V. Smith, P. Broussard, and M. Small, "Amniotic fluid volume assessment with the four-quadrant technique at 36-42 weeks' gestation," Journal of Reproductive Medicine for the Obstetrician and Gynecologist, vol. 32, no. 7, pp. 540-542, 1987.

[21] H. L. Hedriana and T. R. Moore, "Ultrasonographic evaluation of human fetal urinary flow rate: accuracy limits of bladder volume estimations," American Journal of Obstetrics and Gynecology, vol. 170, no. 5, pp. 1250-1254, 1994.

[22] R. H. Stigter, L. J. Van Schelven, H. W. Bruinse, E. J. H. Mulder, and M. J. C. Van Gemert, "On the measurement of fetal bladder volume and urine production: methodological considerations," Prenatal and Neonatal Medicine, vol. 5, no. 3, pp. 169-176, 2000.

[23] S. Campbell, J. W. Wladimiroff, and C. J. Dewhurst, "The antenatal measurement of fetal urine production," The Journal of Obstetrics and Gynaecology of the British Commonwealth, vol. 80, no. 8, pp. 680-686, 1973.

[24] R. Rabinowitz, M. T. Peters, S. Vyas, S. Campbell, and K. H. Nicolaides, "Measurement of fetal urine production in normal pregnancy by real-time ultrasonography," American Journal of Obstetrics and Gynecology, vol. 161, no. 5, pp. 1264-1266, 1989.

[25] R. H. Stigter, E. J. H. Mulder, and G. H. A. Visser, "Hourly fetal urine production rate in the near term fetus: is it really increased during fetal quiet sleep?" Early Human Development, vol. 50, no. 3, pp. 263-272, 1998.

[26] L. C. Van Otterlo, J. W. Wladimiroff, and H. C. S. Wallenburg, "Relationship between fetal urine production and amniotic fluid volume in normal pregnancy and pregnancy complicated by diabetes," British Journal of Obstetrics and Gynaecology, vol. 84, no. 3, pp. 205-209, 1977.

[27] H. Takeuchi, T. Koyanagi, T. Yoshizato, T. Takashima, S. Satoh, and H. Nakano, "Fetal urine production at different gestational ages: correlation to various compromised fetuses in utero," Early Human Development, vol. 40, no. 1, pp. 1-11, 1994.

[28] M. E. Wlodek, G. D. Thorburn, and R. Harding, "Bladder contractions and micturition in fetal sheep: their relation to 
behavioral states," American Journal of Physiology, vol. 257, no. 6, p. 26/6, 1989.

[29] L. J. Groome, F. L. Gaudier, J. C. Hauth, J. Owen, C. L. Neely, and S. P. Cliver, "Cross-sectional study examining the relationship between fetal urine production and the amniotic fluid index at 38-43 weeks of gestation," Journal of MaternalFetal Investigation, vol. 2, no. 3, pp. 117-120, 1993.

[30] L. J. Minei and K. Suzuki, "Role of fetal deglutition and micturition in the production and turnover of amniotic fluid in the monkey," Obstetrics and Gynecology, vol. 48, no. 2, pp. 177-181, 1976.

[31] H. Oosterhof, V. D. J. G. Stege, M. Lander, H. F. R. Prechtl, and J. G. Aarnoudse, "Urine production rate is related to behavioural states in the near term human fetus," British Journal of Obstetrics and Gynaecology, vol. 100, no. 10, pp. 920922, 1993.

[32] R. H. Stigter, E. J. H. Mulder, H. W. Bruinse, and G. H. A. Visser, "Doppler studies on the fetal renal artery in the severely growth-restricted fetus," Ultrasound in Obstetrics and Gynecology, vol. 18, no. 2, pp. 141-145, 2001. 


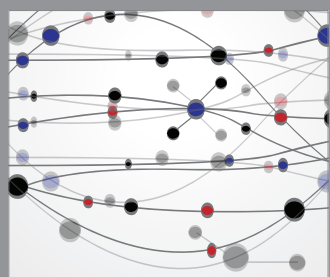

The Scientific World Journal
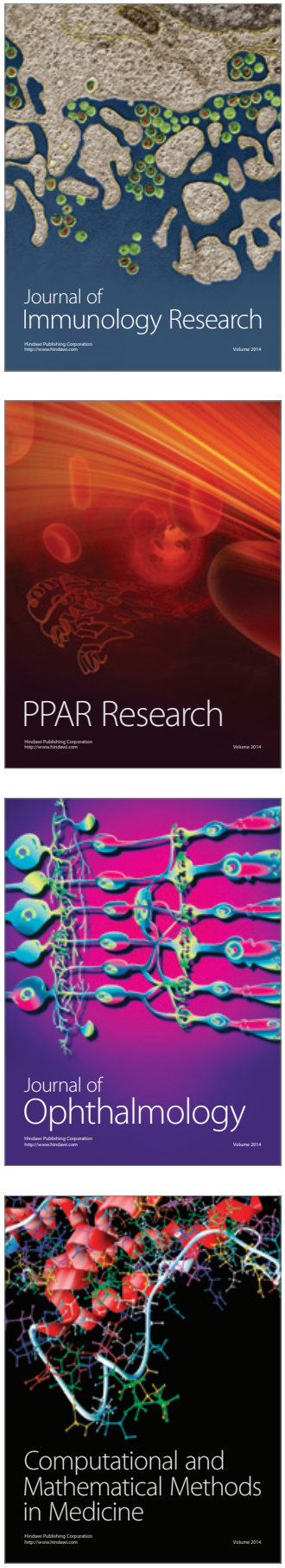

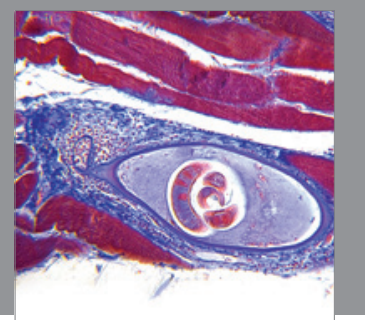

Gastroenterology

Research and Practice
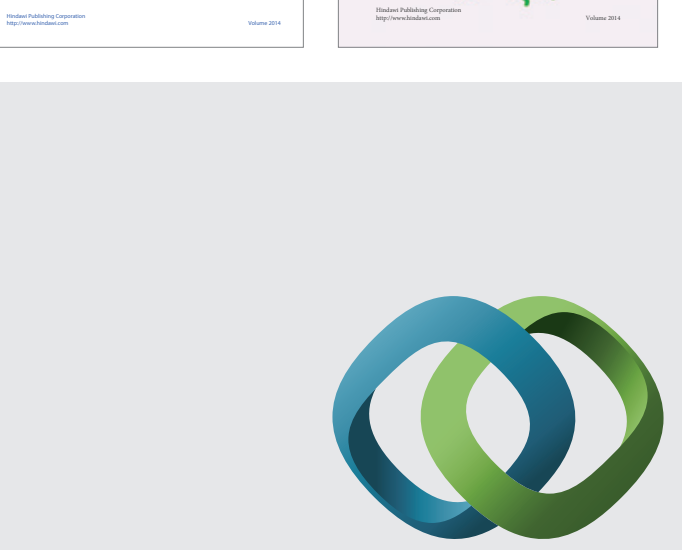

\section{Hindawi}

Submit your manuscripts at

http://www.hindawi.com
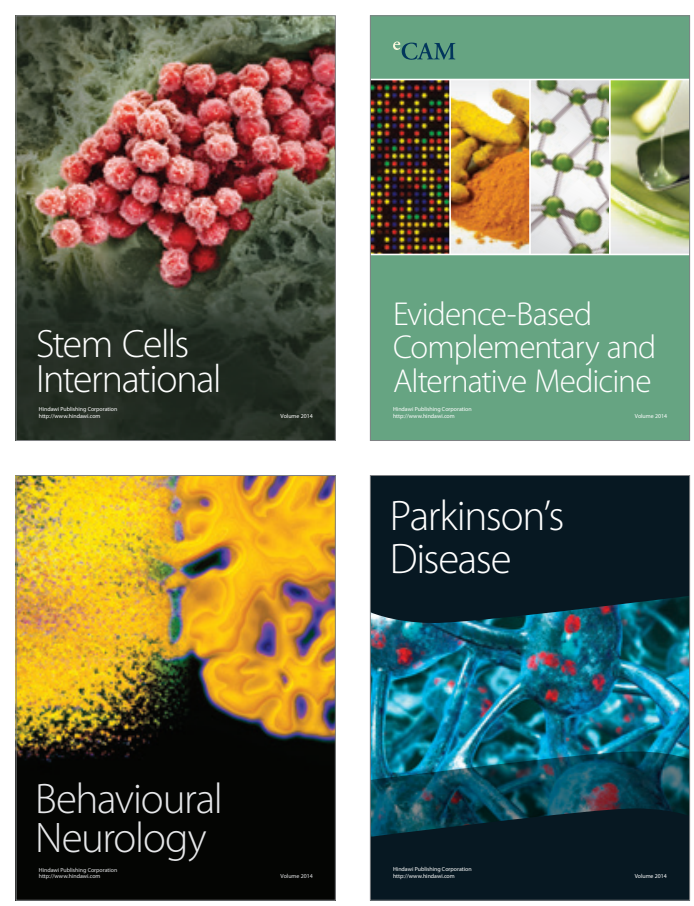

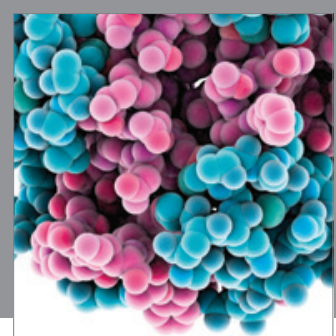

Journal of
Diabetes Research

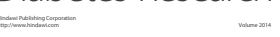

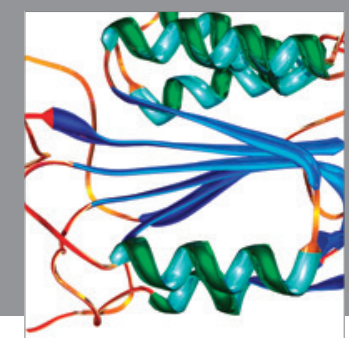

Disease Markers
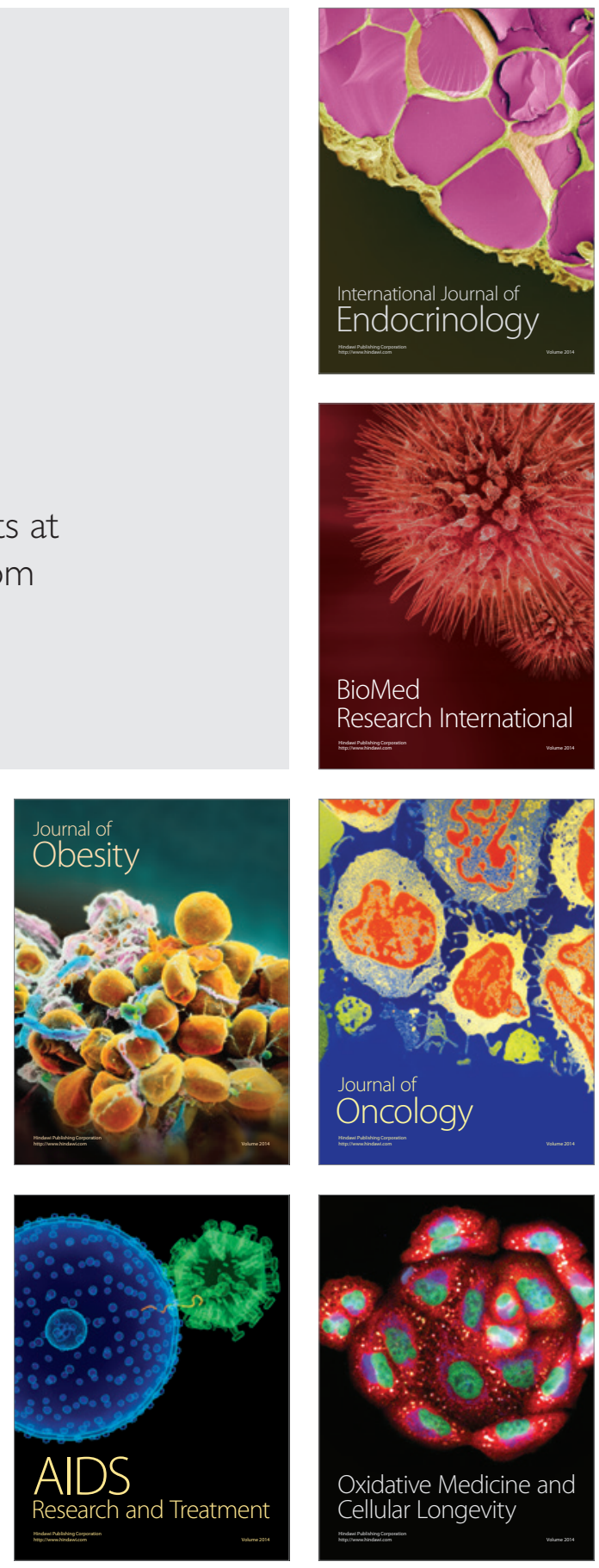